\title{
KENDALA DAN SOLUSI IMPLEMENTASI SUBSIDI BENIH PADI DI PROVINSI SUMATERA SELATAN
}

\author{
Valeriana Darwis \\ Pusat Penelitian Sosial Ekonomi dan Kebijakan Pertanian \\ Email: valerianadrwis@yahoo.co.id
}

\begin{abstract}
Seed is one of the main elements in rice cultivation. Use of seed labeled and quality will have a positive impact on productivity. This strategic role of seed which is the reason the government helps farmers by conducting seed subsidies. Subsidization of seed carried out throughout Indonesia and one of them is the province of South Sumatra. The objective is to see the implementation of subsidized seeds with the main focus of the implementation challenges and solutions such activities. By 2016 subsidy survay seed at the time of implementation was not up to 10 percent. The main cause of this low uptake by PSO is a delay DUPBB that the main basis of PSO prepares and provides rice seeds. Despite the low uptake but seed subsidies still need to be passed on, this is due to the use of seed labeled and quality in South Sumatra Province is still low, and to overcome implementation seed subsidies in the future need to be increased dissemination activities, the introduction of new varieties of $R \& D$, the certainty of the selection of varieties, increasing the number of seeds subsidized and incentives for enumerators DUPBB.
\end{abstract}

Keywords: constraints, solutions and seed subsidy

\begin{abstract}
Abstrak : Benih merupakan salah satu unsur utama dalam budidaya padi. Pemakaian benih berlabel dan bermutu akan memberikan dampak positif pada produktivitas. Peranan benih yang strategis ini merupakan alasan pemerintah membantu petani dengan melaksanakan kegiatan subsidi benih. Pemberian subsidi benih dilakukan diseluruh Indonesia dan salah satunya adalah Provinsi Sumatera Selatan. Tujuan penulisan ini adalah melihat pelaksanaan subsidi benih dengan fokus utama kendala dan solusi implementasi dari kegiatan tersebut. Pada tahun 2016 subsidi benih pada saat dilakukan survay pelaksanaannya tidak sampai 10 persen. Penyebab utama serapan rendah ini menurut PSO adalah keterlambatan DUPBB yang menjadi dasar utama PSO menyiapkan dan memberikan benih padi. Meskipun rendah serapan tetapi subsidi benih masih perlu diteruskan, hal ini disebabkan pemakaian benih berlabel dan bermutu di Provinsi Sumatera Selatan masih rendah, Dan untuk mengatasi kendala implementasi subsidi benih kedepannya perlu ditingkatkan sosialisasi kegiatan, pengenalan varietas baru litbang, kepastian pemilihan varietas, penambahan jumlah benih yang disubsidi dan pemberian insentif bagi petugas pendata DUPBB.
\end{abstract}

Kata kunci : kendala, solusi dan subsidi benih

\section{PENDAHULUAN}

Benih merupakan salah satu unsur utama dalam budidaya pertanian. Pemilihan benih akan menentukan produksi dan kualitas komoditas pertanian. Dengan begitu strategisnya peranan benih, maka pemerintah memasukkan benih sebagai salah satu unsur utama dalam mewujudkan kedaulatan pangan. Menurut Sekjen Kementerian Pertanian Hari Priyono saat membuka Seminar Nasional Perlindungan Varietas Tanaman ke-5 di Hotel Utami, Sidoarjo (25/11/10), ada tiga komponen utama yang diperlukan dalam upaya membangun kemandirian perbenihan di Indonesia. Yaitu, pengembangan varietas unggul baru, 
pengembangan kualitas benih, dan aspek penggunaannya, baik dari segi penyebaran maupun pengawasan dan pengendaliannya.

Dalam sistem perbenihan Kementerian Pertanian (2006) membagi sistem perbenihan ke dalam empat sub sistem, yaitu : (i) subsistem penelitian dan pengembangan, (ii) subsistem produksi dan distribusi benih, (iii) subsistem pengendalian mutu dan (iv) subsistem informasi. Subsistem produksi dan distribusi benih padi dilakukan oleh produsen BUMN, swasta dan perorangan. Dengan adanya subsistem tersebut, maka pemerintah melaksanakan kegiatan subsidi benih mengikutsertakan BUMN (PT Sang Hyang Sri dan PT Pertani) dalam menyediakan dan mendistribusikan benih bersubsidi ke petani padi.

Menurut Badan Litbang Kementerian Pertanian (2005) produksi padi nasional lebih banyak disumbangkan dari peningkatan produktivitas $(56,2 \%)$ dan produktivitas bisa meningkat karena adanya inovasi teknologi. Salah satu inovasi teknologi di tingkat petani adalah mempergunakan varietas dan benih berlabel. Menurut Robert. A (2013) benih merupakan faktor penentu dalam meningkatkan produktifitas selain pemakaian pupuk, lingkungan dan faktor sosial ekonomi masyarakat setempat. Oleh karena itu kegiatan subsidi benih padi dilaksanakan dalam rangka meningkatkan produktivitas dan produksi padi dengan cara menyediakan benih padi varietas unggul bersertifikat yang memenuhi aspek kualitas dan kuantitas. Selain itu kegiatan ini juga membantu petani dalam mengurangi beban usahatani khususnya dalam penggadaan benih.

Untuk benih padi pemerintah memiliki dua jenis penggadaan, yaitu melalui Bantuan Langsung Benih Unggul (BLBU) dan subsidi benih. Khusus untuk kegiatan subsidi benih, pemerintah telah menyiapkan anggaran sebanyak Rp. 1 triliyun pada tahun 2016. Kegiatan ini akan dilaksankan di 31 provinsi dengan luasan kegiatan 3.900.000 ha dan benih yang dibutuhkan sebanyak $97.500 .000 \mathrm{~kg}$. Dalam pelaksanaannya benih disediakan dan didistribusikan oleh PT Sang Hyang Seri (Persero) dan PT Pertani (Persero) dengan masing-masing sebanyak $48.750 .000 \mathrm{~kg}$.

Dengan penjelasan diatas, maka tulisan ini bertujuan ingin mengetahui pelaksanaan kegiatan subsidi benih di Provinsi Sumatera Selatan, khususnya kendala dan solusi dalam mengatasinya.

\section{METODOLOGI}

Tulisan ini merupakan bagian dari kajian Review Kebijakan Penyediaan Dan Penyaluran Benih Padi Bersubsidi yang dilaksanakan oleh Biro Perencanaan Sekjen Kementerian Pertanian pada tahun anggaran 2016. Kajian dilakukan di beberapa provinsi sentra produksi padi dan salah satunya adalah provinsi Sumatera Selatan. Survay ke Provinsi Sumatera Selatan dilakukan pada pertengahan bulan Oktober.

Tulisan ini mempergunakan data primer dan sekunder. Data primer diperoleh melalui tiga cara yaitu : pertama dengan cara memberikan kuesioner kepada stake holder yang terkait dengan kegiatan subsidi benih, kedua melakukan FGD dengan stake holder tersebut dan ketiga melakukan wawancara langsung mempergunakan kuesioner dengan PPL dan kios tani. Pelaksanaan FGD dilaksanakan di kantor Dinas Pertanian Sumatera Selatan dan dihadiri oleh : perwakilan Dinas Pertanian Provinsi, BPSB, PT Sang Hyang Sri, PT. Pertani, UPTD Perbenihan, Asosiasi Produsen Benih, Penangkar dan Petani. Wawancara Kios tani dan PPL diwakili oleh pedagang dan petugas yang ada di Kabupaten Ogan Ilir. Data sekunder diperoleh dari Direktorat Jenderal Tanaman Pangan, Balai Penelitian Padi Sukamandi dan Dinas Pertanian Provinsi Sumatera Selatan. Data-data yang terkumpul kemudian dianalisis dengan mempergunakan metode deskriptif dan disajikan dalam bentuk tabel dan gambar.

\section{HASIL PEMBAHASAN}

\section{Perkembangan Varietas Unggul}

Para pemulia telah banyak menghasilkan varietas dari berbagai jenis tanaman padi yang memiliki keunggulan dalam daya hasil, resistensi terhadap hama dan penyakit, toleransi terhadap cekaman abiotik, dan mutu hasil. Keunggulan tersebut disalurkan dari tangan pemulia kepada pengguna (customers) melalui benih. Artinya suatu varietas unggul akan dirasakan manfaatnya oleh pengguna hanya 
bila benih bermutu dari varietas tersebut tersedia dalam skala komersial. Bermutu berarti benih tersebut harus asli (genuine, authentic, true-to-variety) agar mampu mencerminkan karakteristik varietas yang diwakilinya sesuai dengan deskripsi, hidup (viable) agar tumbuh bila ditanam, sehat (healthy) agar tidak menyebarkan penyakit terbawa benih (seedborne diseases) dan bersih (terutama dari biji gulma) agar tidak menjadi sumber infestasi gulma.

Perakitan varietas unggul padi di Indonesia dimulai tahun 1920-an dengan memanfaatkan gene pool yang dibentuk melalui introduksi tanaman. Las et al.2004 secara umum memilah perkembangan teknologi perakitan varietas unggul padi ke dalam 3 periode, yaitu era sebelum 1970-an hingga sebelum swasembada beras (pra-IR64) dan era pasca swasembada beras (era IR64). Pada era sebelum tahun 1970-an pemuliaan padi diarahkan pada pembentukan varietas untuk lahan sawah tadah hujan yang kurang subur atau varietas yang kurang responsive terhadap pemupukan.

Pada era tahun 1970-an hingga sebelum swasembada beras tercapai, tujuan perakitan varietas padi selain meningkatkan potensi hasil juga diarahkan untuk memperbaiki rasa nasi. Dua varietas padi dari IRRI IR8 dan IR5 yang mempunyai potensi hasil 4,5-5,5 t/ha digunakan sebagai sumber gen untuk memperbaiki sifat-sifat varietas unggul yang sudah ada. Program perakitan varietas padi pada era saat ini diarahkan untuk memperbaiki ketahanan terhadap hama dan penyakit utama. Diantara berbagai varietas unggul yang dilepas pada era tersebut, varietas Cisadane yang tahan terhadap hama wereng batang coklat biotipe 1 dan 2 berkembang pesat di kalangan petani dan menjadi kontributor utama dalam swasembada beras tahun 1984. Namun popularitas Cisadane kemudian digantikan oleh varietas IR64 yang tahan terhadap batang coklat biotipe 3 dengan rasa nasi enak.

Sejak tahun 1974 jumlah varietas unggul padi introduksi dari IRRI semakin banyak termasuk di antaranya PB36 (1978) dan IR64 (1986) yang sangat fenomenal di Indonesia dan sangat dominan pada masanya. Varietas padi introduksi IRRI yang terakhir dilepas pada tahun 1993, yaitu IR68. Pada tahun 2010 dilepas dua varietas unggul baru yang merupakan hasil kerja sama Badan Litbang Pertanian dengan IRRI, yaitu Inpara 4 dan Inpara 5. Perkembangan benih di dalam negeri dari tahun 1940 hingga April 2015 telah dilepas sekitar 390 varietas padi yang merupakan hasil pemuliaan institusi pemerintah (termasuk Badan Litbang Pertanian), perguruan tinggi maupun swasta; baik hasil pemuliaan di dalam negeri, pemutihan varietas lokal, atau introduksi dari luar negeri. Varietas yang dilepas tersebut berupa padi inbrida dan hibrida. Perkembangan jumlah varietas padi yang dilepas di Indonesia per tahunnya dapat dilihat pada Gambar.1

Selain hasil pemuliaan, varietas unggul yang dilepas juga berasal dari varietas lokal yang keunggulannya sudah diuji dan dilepas secara nasional. Varietas Genjah Lampung yang dilepas pada tahun 1960 dan varietas Seratus Malam yang dilepas tahun 1961 merupakan varietas hasil seleksi galur padi yang tumbuh di Provinsi Lampung. Hingga April 2015, telah dilepas secara nasional sekitar 23 varietas padi lokal. Varietas padi lokal yang dilepas secara nasional lainnya adalah Arias (Sumut) ; Rojolele (Jateng) ; Pandan Wangi dan Sarinah (Jabar) ; Pare Wangi (NTT) ; Cekau Pelalawan dan Karya Pelalawan (Riau) ; Siam Mutiara, Siam Saba, dan Buyung (Kalsel), Segreng Handayani dan Mendel Handayani (DIY) ; serta Anak Daro, Junjuang, Kuriak Kusuik, Ceredek Merah, Segenggam Panuah, Siarang, Sigudang, Bawaan, dan Lampai Kuniang (Sumbar).

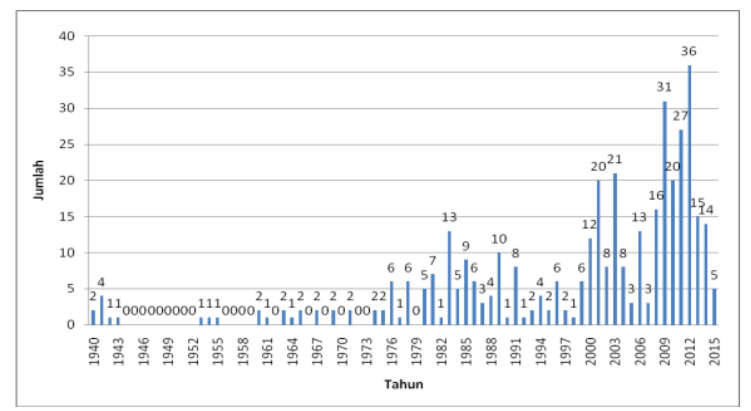

Sumber: Puslitbangtan (2009), BPTP Jateng (2014), Balitbangtan (2015), Direktorat Perbenihan (2015a), diolah

Gambar 1. Perkembangan Jumlah Varietas Padi yang Dilepas di Indonesia, 1940-2015 
Telah banyak varietas unggul yang telah dilepas ke masyarakat, namun hanya sebagian kecil yang diadopsi secara luas oleh petani. Kurangnya informasi yang diterima petani mengenai varietas unggul yang telah dihasilkan dan dilepas merupakan salah satu penghambat adopsi varietas unggul yang dihasilkan, di samping faktor-faktor lain yang menjadi pertimbangan petani yang melekat dengan karakteristik varietas unggul tersebut, seperti umur tanaman, produktivitas, daya tahan terhadap serangan hama dan penyakit, rasa nasi yang enak, serta pertimbangan ekonomi seperti harga pasar atau kemudahan memasarkan, dan sebagainya. Faktor-faktor tersebut menyebabkan beberapa varietas unggul tertentu diadopsi secara luas dan menjadi dominan dalam suatu periode waktu, namun varietas unggul yang lainnya tidak berkembang di kalangan petani.

Varietas unggul yang telah dilepas pada umumnya disebarluaskan melalui Dinas Pertanian (penyuluh), Balai Benih Induk (BBI), dan penangkar benih. Namun, sebagian petani memperoleh informasi bukan dari penyuluh, melainkan dari kelompok tani, petani lain, atau kios pertanian. Kurangnya akses petani terhadap informasi teknologi padi modern menyebabkan lambatnya dan rendahnya adopsi varietas unggul baru hasil pemuliaan lembaga penelitian. Hal ini sejalan dengan hasil studi Hammer (2003), yaitu di negara berkembang kurangnya akses terhadap teknologi menjadi penyebab terpeliharanya cara-cara bertani tradisional oleh sebagian besar petani kecil.

Disamping itu alasan petani dalam mengadopsi varietas padi baru adalah potensi hasil tinggi, permintaan pasar/harga jual tinggi, rasa nasi enak, tahan terhadap hama dan penyakit, dan umur genjah. Petani mengharapkan benih varietas unggul memberikan hasil tinggi dengan mutu yang baik sehingga menguntungkan mereka (Las et al., 2004). Secara umum, Wale (2011) menunjukkan bahwa absennya sifat-sifat yang disukai petani dan terdapatnya sifat-sifat yang tidak dapat diterima oleh petani merupakan variable (variety-dependent qualities) yang menentukan adopsi varietas tanaman padi oleh petani.

Sebagai contoh, jika petani menganggap padi hibrida yang dikategorikan sebagai suatu inovasi (Rogers, 2003) memiliki karakter lebih unggul baik fisiologi maupun ekonomi dibandingkan varietas yang digunakan sebelumnya mereka akan mengadopsi dan sebaliknya. Dengan demikian, keberadaan media untuk proses pengenalan dan diseminasi padi hibrida seperti program SL-PTT menjadi sangat penting. Dari program tersebut petani selanjutnya melakukan evaluasi tentang kelayakan padi hibrida baik secara teknis, sosial, maupun ekonomi (Ashari dan Rusastra, 2014).

Banyak faktor yang menjadi pertimbangan peneliti atau pemulia dalam mengembangkan varietas padi. Pertimbangan tersebut tidak hanya terbatas pada potensi hasil, tetapi termasuk pertimbangan umur tanaman, tinggi tanaman, ketahanan terhadap cekaman biotik dan abiotik, bahkan rasa atau tekstur nasinya. Perkembangan varietas padi oleh peneliti dan pemulia padi tidak hanya menghasilkan padi yang sesuai untuk satu jenis lahan, tetapi juga menghasilkan varietas yang mampu beradaptasi dengan baik untuk beberapa jenis lahan sekaligus. Hal ini menjadi penting mengingat jenis lahan padi di Indonesia cukup beragam dan kondisi lingkungan tumbuh seringkali cepat berubah. Beberapa varietas padi yang cocok untuk beberapa jenis lahan ditampilkan pada Tabel 1.

\section{Posisi Provinsi Sumatera Selatan Terhadap Produksi Padi Nasional}

Produksi padi nasional dari tahun 2012-2015 meningkat dari 69.056.126 ton GKG pada tahun 2012 menjadi 75.397.641 ton GKG pada tahun 2015 (Tabel 2). Tetapi sebaliknya provitas padi perhektar mengalami penurunan dari 51,36 ku/ha menjadi 51,35 ku/ha. Dalam kurun waktu 4 tahun tersebut sumbangan produksi padi nasional banyak berasal dari 3 provinsi besar di Jawa (Jatim, Jabar, Jateng), sementara provinsi terbesar yang memberikan kontribusi produksi padi diluar Pulau Jawa adalah Provinsi Sulawesi Selatan dan Sumatera Selatan.

Secara nasional produksi padi di Provinsi Sumatera Selatan berada di peringkat kelima. Pada tahun 2012 sampai 2015 produksi padi di Provinsi Sumatera Selatan mengalami kenaikan yang sangat siginifikan, yaitu dimulai pada tahun 2012 sebesar 3.295.247 ton GKG, meningkat menjadi 3.676.723 ton GKG pada tahun 2013, pada tahun 2014 menurun sedikit menjadi 3.670.435 ton GKG dan pada tahun 
Tabel 1. Nama-Nama Varietas Padi yang Cocok untuk Beberapa Agroekosistem di Indonesia, 1983-1991

\begin{tabular}{ccll}
\hline $\begin{array}{c}\text { No. } \\
\text { Tahun } \\
\text { Dilepas }\end{array}$ & \multicolumn{1}{c}{ Varietas } & \multicolumn{1}{c}{ Agroekosistem } \\
\hline 1 & 1983 & Mahakam & Padi Lebak/Pasang Surut \\
2 & 1976 & Gata & Padi Sawah/Gogo/Gogo Rancah \\
3 & 1976 & Gati & Padi Sawah/Gogo/Gogo Rancah \\
4 & 1978 & PB36 & Padi Sawah/Gogo Rancah \\
5 & 1987 & Dodokan & Padi Sawah/Gogo Rancah \\
6 & 1987 & Jangkok & Padi Sawah/Gogo Rancah \\
7 & 1989 & IR 66 & Padi Sawah/Gogo Rancah \\
8 & 1989 & Laut Tawar & Padi Sawah/Gogo \\
9 & 1991 & Cenranae & Padi Sawah/Gogo/Gogo Rancah \\
10 & 1991 & Danau Tempe & Padi Sawah/Gogo \\
11 & 1991 & IR74 & Padi Sawah/Gogo Rancah \\
12 & 1999 & Towuti & Padi Sawah/Gogo \\
13 & 2001 & Wera & Padi Sawah/Gogo \\
14 & 1961 & Barito & Padi Sawah/Lebak/Pasang Surut \\
15 & 1980 & PB42 & Padi Sawah/Lebak/Pasang Surut \\
16 & 1988 & Musi & Padi Sawah/Lebak/Pasang Surut \\
17 & 1984 & Kapuas & Padi Sawah/Pasang Surut \\
18 & 1991 & Lematang & Padi Sawah/Pasang Surut \\
19 & 1991 & Sei Lilin & Padi Sawah/Pasang Surut \\
\hline
\end{tabular}

Sumber: Puslitbangtan (2009), BPTP Jateng (2014), Balitbangtan (2015), Direktorat Perbenihan (2015a), diolah
2015 meningkat sangat signifikan menjadi 4.247.922 ton GKG. Peningkatan dan penurunan produksi ini disebabkan salah satunya oleh produktivitas padi perhektarnya yang juga mengalami perubahan dengan masing-masing produktivitasnya adalah 42,82 $\mathrm{ku} /$ ha tahun 2012, naik menjadi 45,96 ku/ha tahun 2013, tahun 2014 turun sedikit menjadi 45,26 ku/ha dan tahun 2015 meningkat menjadi $48.67 \mathrm{ku} / \mathrm{ha}$.

Kalau dilihat secara nasional kontribusi produksi padi Sumatera Selatan terhadap produksi nasional masing-masing sebesar : 4,78\% (2012), 5,16\% (2013), 5,18\% (2014) dan $5,63 \%$ (2015). Sementara produktivitas padi Sumatera Selatan dengan produktivitas padi nasional perbedaannya $-8.55 \mathrm{ku} / \mathrm{ha}$ (2012), turun menjadi $-5.56 \mathrm{ku} / \mathrm{ha}$ (2013), naik menjadi -6.09 ku/ha (2014), dan perbedaannya menjadi turun drastis menjadi $-2.68 \mathrm{ku} / \mathrm{ha}$ pada tahun 2015. Kalau berdasarkan data tersebut terlihat peranan produksi dan produktivitas padi Provinsi Sumatera Selatan menunjukan peningkatan yang berarti (positif).

Tabel 2. Produksi dan Produktivitas Padi Nasional

\begin{tabular}{llrrrrrrrr}
\hline \multirow{2}{*}{ No Provinsi } & \multicolumn{2}{c}{2012} & \multicolumn{2}{c}{2013} & \multicolumn{2}{c}{2014} & \multicolumn{2}{c}{2015} \\
& & Produksi & Provitas & Produksi & Provitas & Produksi & Provitas & Produksi & Provitas \\
\hline 1 & Jawa Timur & 12.198 .707 & 61.74 & 12.049 .405 & 59.15 & 12.397 .049 & 59.81 & 13.154 .967 & 61.13 \\
2 & Jawa Barat & 11.271 .861 & 58.74 & 12.083 .162 & 59.53 & 11.644 .899 & 58.82 & 11.373 .144 & 61.22 \\
3 & Jawa Tengah & 10.232 .934 & 57.7 & 10.344 .820 & 56.06 & 9.648 .104 & 53.57 & 11.301 .422 & 50.25 \\
4 & Sul-Sel & 5.003 .011 & 50.98 & 5.035 .830 & 51.22 & 5.426 .097 & 52.17 & 5.471 .806 & 52.41 \\
$\mathbf{5}$ & Sum-Sel & $\mathbf{3 . 2 9 5 . 2 4 7}$ & $\mathbf{4 2 . 8 1}$ & $\mathbf{3 . 6 7 6 . 7 2 3}$ & $\mathbf{4 5 . 9 6}$ & $\mathbf{3 . 6 7 0 . 4 3 5}$ & $\mathbf{4 5 . 2 6}$ & $\mathbf{4 . 2 4 7 . 9 2 2}$ & $\mathbf{4 8 . 6 7}$ \\
6 & Sum-Ut & 3.715 .514 & 48.56 & 3.708 .314 & 50.17 & 3.631 .039 & 50.62 & 4.044 .829 & 51.74 \\
7 & Lampung & 3.101 .455 & 48.32 & 3.221 .104 & 50.26 & 3.320 .064 & 51.18 & 3.641 .895 & 51.49 \\
8 & Sum-Bar & 2.368 .390 & 49.71 & 2.430 .384 & 49.82 & 2.519 .020 & 50.06 & 2.550 .609 & 50.25 \\
9 & NTB & 2.114 .231 & 49,69 & 2.193 .698 & 50.08 & 2.116 .637 & 48.8 & 2.417 .392 & 51.71 \\
10 & Kal-Sel & 2.086 .221 & 42.05 & 2.031 .029 & 42.34 & 2.094 .590 & 42.05 & 2.140 .276 & 41.87 \\
11 & Banten & 1.865 .893 & 51.45 & 2.083 .609 & 52.92 & 2.045 .883 & 52.95 & 2.188 .996 & 56.61 \\
12 & Aceh & 1.788 .738 & 46.12 & 1.956 .940 & 48.68 & 1.820 .062 & 48.39 & 2.331 .046 & 50.56 \\
& Jumlah & 59.042 .202 & & 60.815 .017 & & 60.333 .879 & & 64.864 .304 & \\
& Nasional & 69.056 .126 & 51.36 & 71.279 .709 & 51.52 & 70.846 .465 & 51.35 & 75.397 .641 & 51.35 \\
\hline
\end{tabular}

Sumber : Dinas Pertanian Sumatera Selatan

Luas Lahan Tanam dan Kebutuhan Benih Padi Provinsi Sumatera Selatan

Berdasarkan jenis lahan Provinsi Sumatera

Selatan termasuk daerah yang banyak airnya
(68.35\%). Hal ini terlihat jenis lahan yang paling besar adalah lahan pasang surut kemudian diikuti oleh lahan lebak. Kontribusi untuk masing-masing lahan dari total lahan 
provinsi tersebut adalah $36.63 \%$ ( 227.334 ha) dan 31.72\% (196.875 ha) (Tabel 3). Kalau berdasarkan luas lahan secara keseluruhan kabupaten yang paling luas kepemilikan lahannya adalah Kabupaten Banyuasin (197.961 ha), kemudian diikuti oleh Kabupaten Ogan Komering Ilir (122.602 ha).

Tabel 3. Lahan Yang Ditanami Padi di Provinsi Sumatera Selatan 2015 (Ha)

\begin{tabular}{|c|c|c|c|c|c|c|}
\hline \multirow[t]{2}{*}{ No } & \multirow[t]{2}{*}{ Kab/kota } & \multicolumn{4}{|c|}{ Jenis Lahan } & \multirow[t]{2}{*}{ Total } \\
\hline & & Irigasi & $\begin{array}{l}\text { Tadah } \\
\text { hujan }\end{array}$ & $\begin{array}{c}\text { Pasang } \\
\text { surut }\end{array}$ & lebak & \\
\hline 1 & Ogan Komering Ulu & 3.244 & 1.648 & 0 & 440 & 5.332 \\
\hline 2 & Ogan Komering Ilir & 650 & 37.1 & 26.434 & 58.418 & 122.602 \\
\hline 3 & Muara Enim & 6.054 & 3.854 & 0 & 14.502 & 24.41 \\
\hline 4 & Lahat & 15.364 & 1.515 & 0 & 0 & 16.879 \\
\hline 5 & Musi Rawas & 12.423 & 7.438 & 0 & 297 & 20.158 \\
\hline 6 & Musi Banyuasin & 0 & 235 & 34.579 & 15.747 & 50.561 \\
\hline 7 & Banyuas in & 0 & 0 & 166.317 & 31.644 & 197.961 \\
\hline 8 & OKU Selatan & 15.957 & 1.924 & 0 & 0 & 17.881 \\
\hline 9 & OKU Timur & 43.481 & 21.108 & 0 & 15.077 & 79.666 \\
\hline 10 & Ogan Ilir & 0 & 553 & 0 & 46.689 & 47.242 \\
\hline 11 & Empat Lawang & 13.05 & 504 & 0 & 0 & 13.554 \\
\hline 12 & PALI & 0 & 315 & 0 & 5.499 & 5.814 \\
\hline 13 & Musi Rawas Utara & 415 & 4.334 & 0 & 2.195 & 6.944 \\
\hline 14 & Palembang & 0 & 0 & 0 & 5.84 & 5.84 \\
\hline 15 & Prabumulih & 0 & 0 & 0 & 525 & 525 \\
\hline 16 & Pagar Alam & 3.412 & 0 & 0 & 0 & 3.412 \\
\hline 17 & Lubuk Linggau & 1.637 & 199 & 14 & 1 & 1.851 \\
\hline & Jumlah & 115.687 & 80.727 & 227.344 & 196.875 & 620.632 \\
\hline
\end{tabular}

Sumber : Dinas Pertanian Sumatera Selatan

Semua jenis lahan yang ada di Provinsi Sumatera Selatan semuanya dapat ditanami padi dan produksi padi tersebut paling banyak dihasilkan dari lahan irigasi. Menurut Dinas Pertanian Provinsi Sumatera Selatan pada tahun 2015 produksi padi di lahan irigasi dapat ditanami satu kali (IP 100) dalam setahun di lahan seluas 9.138 ha, ditanami dua kali (IP 200) setahun di lahan seluas 74.596 ha dan dapat ditanami tiga kali (IP 300) setahun dilahan seluas 31.953 ha (Tabel 4).

Kondisi yang sama juga terjadi di lahan tadah hujan yang bisa ditanami satu kali setahun seluas 25.269 ha, dua kali tanam setahun seluas 54.378 ha dan tiga kali setahun pada luasan 1.080 ha. Lahan tadah hujan yang bisa ditanami tiga kali adalah lahan tadah hujan yang berada dekat dengan sumber air dan kabupaten yang paling tinggi luas tanamnya adalah Kabupaten Musi Banyuasin (108.453 ha). Sementara pada lahan pasang surut dan lebak hanya bisa ditanami (IP) dua kali setahun, yaitu masing-masing dengan luasan : IP 1 seluas 131.936 ha dan IP 2 seluas 95.408 ha pada lahan pasang surut di lahan lebak IP 1, seluas 166.908 ha dan IP 2, seluas 29.966.

Tabel 4. Penggunaan Lahan Untuk Tanaman Padi

\begin{tabular}{llrcr}
\hline No & $\begin{array}{c}\text { Tipologi } \\
\text { Lahan }\end{array}$ & $\begin{array}{c}1 \mathrm{x} \\
\text { Tanam }\end{array}$ & $\begin{array}{c}2 \mathrm{x} \\
\text { Tanam }\end{array}$ & $\begin{array}{c}3 \mathrm{x} \\
\text { Tanam }\end{array}$ \\
\hline 1 & Irigasi & 9.138 & 74.596 & 31.953 \\
2 & Tadah & 25.269 & 54.378 & 1.080 \\
3 & hujan & 131.936 & 95.408 & 0 \\
4 & Pasang & 166.908 & 29.966 & 0 \\
& surut & & & \\
& Lebak & & & \\
& Jumlah & 333.251 & 254.348 & 33.033 \\
\hline
\end{tabular}

Sumber : Dinas Pertanian Sumatera Selatan

Salah satu faktor penentu produktivitas padi adalah penggunaan benih dan kebutuhan benih di Provinsi Sumatera Selatan meningkat mengikuti penambahan luas panen. Pada tahun 2014 luas tanam 812.822 ha dan kebutuhan benihnya sebanyak $20.320 .550 \mathrm{~kg}$, kemudian kebutuhan meningkat menjadi $22.355 .500 \mathrm{~kg}$ pada tahun 2015 dan meningkat lagi menjadi $27.539 .725 \mathrm{~kg}$ pada tahun 2016 (Tabel 5). Tetapi dalam kenyataannya sebenarnya kebutuhan benih padi jauh lebih banyak dari yang diproyeksikan. Hal ini disebabkan perhitungan proyeksi yang dipergunakan selama ini kebutuhan benih dalam satu hektarnya disamakan dan tidak membedakan jenis lahan, yaitu sebanyak $25 \mathrm{~kg} / \mathrm{ha}$. Sementara lahan lebak dan pasang surut umumnya mempergunakan benih padi antara 40 sampai $60 \mathrm{~kg}$ perhektar. Penyebab banyaknya pemakaian benih di lahan tersebut karena petani tidak bisa memprediksi ketersediaan air. Terutama di lahan lebak benih padi sudah disiapkan dan sudah siap di tanam, tetapi lahan masih tergenang oleh air. Akhirnya benih tersebut tidak bisa dipergunakan secara optimal dan solusi satu-satunya adalah menyiapkan benih baru. 
Valeriana Darwis: Kendala dan Solusi Implementasi Subsidi Benih...

Tabel 5. Pemakaian dan Proyeksi Kebutuhan Benih Padi Inbrida Provinsi Sumatera Selatan

\begin{tabular}{|c|c|c|c|c|c|c|c|}
\hline \multirow[t]{2}{*}{ No } & \multirow[t]{2}{*}{ Kab/Kota } & \multicolumn{2}{|c|}{2014} & \multicolumn{2}{|c|}{2015} & \multicolumn{2}{|c|}{2016} \\
\hline & & $\begin{array}{c}\text { Luas } \\
\text { Tanam }\end{array}$ & Kebutuhan & $\begin{array}{c}\text { Luas } \\
\text { Tanam }\end{array}$ & Kebutuhan & $\begin{array}{c}\text { Luas } \\
\text { Tanam }\end{array}$ & Kebutuhan \\
\hline 1 & OKU & 14.231 & 355.775 & 13.003 & 325.075 & 14.369 & 359.225 \\
\hline 2 & OKI & 132.019 & 3.300 .475 & 142.503 & 3.562 .575 & 184.404 & 4.610 .095 \\
\hline 3 & Muara Enim & 42.967 & 1.074 .175 & 34.323 & 858.075 & 35.362 & 884.038 \\
\hline 4 & Pali & 2.955 & 73.875 & 8.689 & 217.225 & 12.097 & 302.43 \\
\hline 5 & Lahat & 34.37 & 859.25 & 33.764 & 644.1 & 39.342 & 983.538 \\
\hline 6 & Musi Rawas & 53.285 & 1.332 .125 & 53.313 & 1.332 .625 & 63.35 & 1.583 .758 \\
\hline 7 & Murarata & 3.302 & 82.55 & 5.505 & 137.625 & 11.052 & 276.295 \\
\hline 8 & Musi Banyusasin & 68.205 & 1.455 .125 & 56.543 & 1.413 .575 & 71.273 & 1.781 .818 \\
\hline 9 & Banyuasin & 209.61 & 5.240 .250 & 264.356 & 6.608 .900 & 355.708 & 8.692 .705 \\
\hline 10 & OKU Selatan & 32.561 & 814.025 & 41.491 & 1.037 .275 & 47.175 & 1.179 .380 \\
\hline 11 & OKU Timur & 134.159 & 3.353 .975 & 145.07 & 3.626 .750 & 163.768 & 4.094 .200 \\
\hline 12 & Ogan Ilir & 49.134 & 1.228 .350 & 46.463 & 1.161 .575 & 50.249 & 1.256 .225 \\
\hline 13 & Empat Lawang & 24.64 & 616 & 29.362 & 734.05 & 31.951 & 798.765 \\
\hline 14 & Palembang & 6.003 & 150.075 & 5.821 & 145.525 & 6.244 & 156.1 \\
\hline 15 & Prabumulih & 518 & 12.95 & 582 & 14.55 & 405 & 10.135 \\
\hline 16 & Pagar Alam & 10.02 & 250.5 & 8.347 & 208.675 & 9.139 & 228.473 \\
\hline 17 & Lubuk Linggau & 4.843 & 121.075 & 5.085 & 127.125 & 5.702 & 142.548 \\
\hline & Jumlah & 812.822 & 20.320 .550 & 894.22 & 22.355 .500 & 1.101 .589 & 27.539 .725 \\
\hline
\end{tabular}

Sumber : Dinas Pertanian Sumatera Selatan

Pelaksanaan Kegiatan Subsidi Benih di Provinsi Sumatera Selatan

Dalam Rangka Pelaksanaan Subsidi Benih 2016. Apabila ada produsen benih swasta/penangkar benih yang ingin ikut serta dalam pelaksanaan subsidi benih, dapat dimungkinkan dengan di bawah koordinasi PT Sang Hyang Seri (Persero) dan PT Pertani (Persero) selaku produsen benih pelaksana PSO subsidi benih. Pelaksana PSO Subsidi Benih dalam penyediaan benih agar melibatkan produsen penangkar penerima kegiatan Pemberdayaan Penangkar Benih dan Desa Mandiri Benih melalui kerja sama produksi maupun kerja sama pemasaran. PSO mendistribusikan benih bersubsidi berdasarkan Daftar Usulan Pembelian Benih Bersubsidi yang selanjutnya disebut DU-PBB adalah daftar usulan petani yang akan membeli benih bersubsidi dan merupakan dokumen turunan dari dokumen CPCL.

Dalam petunjuk teknis mekanisme pelaksanaan penjualan dan penyaluran benih bersubsidi dengan pola tertutup, yaitu produsen benih pelaksana PSO subsidi benih akan menjual dan menyalurkan benih bersubsidi sampai ke lokasi kelompok tani. Mekanismenya adalah sebagai berikut : DUPBB yang sudah diverifikasi dan disetujui oleh petugas yang ditugaskan Kepala Dinas Pertanian Kabupaten/Kota (KCD atau KUPTK atau petugas pertanian lainnya) sesuai, diajukan ke PSO subsidi benih. PSO menyampaikan rekapitulasi DU-PBB Kabupaten/Kota kepada Direktur Jenderal Tanaman Pangan (Dirjen TP) untuk diverifikasi. Untuk benih bersubsidi yang berasal dari luar provinsi sebelum dijual dan disalurkan, PSO wajib melakukan pengecekan fisik benih ke BPSBTPH.

Dalam Tahun Anggaran 2016 alokasi benih padi inbrida bersubsidi di Provinsi Sumatera Selatan sebanyak 5 juta $\mathrm{kg}$ yang diperuntukan untuk lahan seluas 200 ribu hektar. Pengadaan benih tersebut diadakan oleh PT SHS dan PT Pertani dengan masing-masing seluas 100 ribu hektar dan benih sebanyak 2,5 
Valeriana Darwis: Kendala dan Solusi Implementasi Subsidi Benih...

Tabel 6. Alokasi Benih Bersubsidi Provinsi Sumatera Selatan 2016

\begin{tabular}{|c|c|c|c|c|c|c|c|c|c|}
\hline \multirow{3}{*}{\multicolumn{2}{|c|}{$\begin{array}{l}\text { No Provinsi } \\
\text { Padi Inbrida }\end{array}$}} & \multicolumn{4}{|c|}{ PT SHS } & \multicolumn{4}{|c|}{ PT.Pertani } \\
\hline & & \multicolumn{2}{|c|}{ Target } & \multicolumn{2}{|c|}{ Realis asi } & \multicolumn{2}{|c|}{ Target } & \multicolumn{2}{|c|}{ Realisasi } \\
\hline & & $\begin{array}{l}\text { Volume } \\
(\mathrm{kg})\end{array}$ & $\begin{array}{l}\text { Luas } \\
\text { (ha) }\end{array}$ & $\begin{array}{l}\text { Volume } \\
(\mathrm{kg})\end{array}$ & $\begin{array}{l}\text { Luas } \\
\text { (ha) }\end{array}$ & $\begin{array}{l}\text { Volume } \\
(\mathrm{kg})\end{array}$ & $\begin{array}{l}\text { Luas } \\
\text { (ha) }\end{array}$ & $\begin{array}{l}\text { Volume } \\
(\mathrm{kg})\end{array}$ & $\begin{array}{l}\text { Luas } \\
\text { (ha) }\end{array}$ \\
\hline 1 & OKU & 125 & 5 & 0 & 0 & - & - & - & \\
\hline 2 & OKI & - & - & - & - & 1.320 .000 & 52.8 & 311.35 & 7.783 \\
\hline 3 & Muara Enim & 125 & 5 & 0 & 0 & - & - & - & - \\
\hline 4 & Pali & - & - & - & - & 25 & 1 & 20.035 & 801 \\
\hline 5 & Lahat & - & - & - & - & 212.5 & 8.5 & 0 & 0 \\
\hline 6 & Musi Rawas & - & - & - & - & 250 & 10 & 0 & 0 \\
\hline 7 & Murarata & - & - & - & - & 50 & 2 & 0 & 0 \\
\hline 8 & Musi Banyuasin & - & - & - & - & 500 & 20 & 105.45 & 4.218 \\
\hline 9 & Banyuasin & 1.225 .000 & 49 & 6.375 & 255 & - & - & - & - \\
\hline 10 & OKU Selatan & 175 & 7 & 0 & 0 & - & - & - & - \\
\hline 11 & OKU Timur & 425 & 17 & 0 & 0 & - & - & - & - \\
\hline 12 & Ogan Ilir & 375 & 15 & $7.093,75$ & 283,75 & - & - & - & - \\
\hline 13 & Empat Lawang & - & - & - & - & 125 & 5 & 0 & 0 \\
\hline 14 & Palembang & - & - & - & - & 5 & 200 & 4.8 & 192 \\
\hline 15 & Prabumulih & 12.5 & 500 & 0 & 0 & - & - & - & - \\
\hline 16 & Pagar Alam & 37.5 & 1.5 & 0 & 0 & - & - & - & - \\
\hline 17 & Lubuk Linggau & - & - & - & - & 12.5 & 500 & 0 & 0 \\
\hline & Jumlah & 2.500 .000 & 100 & $13.468,75$ & 538,75 & 2.500 .000 & 100 & 441.635 & 12.995 \\
\hline \multicolumn{10}{|c|}{ Padi Hibrida } \\
\hline 1 & OKU & - & - & - & - & 3.75 & 250 & 0 & 0 \\
\hline 2 & OKU Timur & 11.25 & 750 & 0 & 0 & - & - & - & - \\
\hline 3 & Banyuasin & - & - & - & - & 7.5 & 500 & 0 & 0 \\
\hline & Jumlah & 11.25 & 750 & 0 & 0 & 11.25 & 750 & 0 & 0 \\
\hline
\end{tabular}

Sumber : Dinas Pertanian Sumatera Selatan, PT SHS, PT Pertani

juta kg. PT SHS mengadakan benih untuk Kabupaten OKU, Muara Enim, Banyuasin, OKU Selatan, OKU Timur Ogan Hilir, Prabumulih dan Pagar Alam. Sementara PT Pertani menyediakan benih bersubsidi untuk Kabupaten OKI, Pali, Lahat, Musi Rawas, Murarata, Musi Banyuasin, Empat Lawang, Palembang dan Lubuk Lingau. Sementara padi Hibrida subsidi benihnya masing-masing PSO sebanyak $11.250 \mathrm{~kg}$ untuk lahan seluas 750 ha. Alokasi subsidi benih sudah diterima PSO pada minggu terakhir bulan Januari, tetapi realisasinya baru terlaksana di minggu pertama bulan Oktober. Sehingga dalam pelaksanaan kegiatan subsidi benih di Provinsi Sumatera Selatan untuk padi Inbrida masih jauh dari target, dari 5 juta $\mathrm{kg}$ benih padi yang ditargetkan baru hanya 455.103,75 kg atau 9,1 persen. Sebaliknya untuk realisasi subsidi benih padi hibrida masih kosong sama sekali (Tabel $6)$.

Beberapa permasalahan kenapa penyerapan benih bersubsidi tidak mencapai 10 persen, diantaranya adalah :

(i) Waktu menanam di tingkat petani bersamaan dengan kegiatan progam peningkatan produksi padi lainnya. Program tersebut menyediakan paket 
Valeriana Darwis: Kendala dan Solusi Implementasi Subsidi Benih...

bantuan serba gratis dan termasuk salah satunya adalah pemberian benih bersertifikat. Sementara benih padi bersubsidi tidak gratis, petani harus membayar Rp 2.500 perkg. Kondisi ini menyebabkan petani lebih baik memilih program pemerintah yang lainnya. Adapun program tersebut antara lain : Upsus padi, intensifikasi, LIJT, peningkatan produktivitas, perluasan tanam, dan lainlain.

(ii) Terlambatnya pengajuan Daftar Usulan Pemberian Benih Bersubsidi (DUPBB) ke PSO. Menurut petugas penyuluh sebenarnya DUPBB sudah disiapkan setiap akhir bulan Desember dan sampai bulan Maret, tetapi dalam pelaksanaannya suka terlambat. Keterlambatan ini dimulai dari mendata petani peserta yang ikut mendapatkan subsidi benih. Petugas yang mendata umumnya adalah penyuluh sukarela yang bekerja tanpa upah. Artinya penyuluh bekerja tidak secara optimal. Daftar DUPBB perdesa yang sudah terdata petani peserta dibawa ke tingkat kecamatan (KCD) dan pengajuan ini juga terlambat disetujui oleh KCD karena menunggu rekapan dari desa-desa yang lainnya. Setelah itu usulan DUPBB dibawa ke Kabupaten dan setelah disetujui oleh bupati baru di ajukan ke dinas pertanian provinsi dan ditembuskan ke PSO. Sementara PSO mendistribusikan benih bersubsidi berdasarkan DUPBB, kalau terlambat mengajukan berarti PSO juga telat memberikan benih bersubsidi ke petani penerima.

(iii) Varietas yang diinginkan petani sering berubah dari jenis awalnya yang disediakan dengan yang diminta, missalkan awalnya diminta Ciherang tetapi dalam permintaan berikutnya dalam DUPBB varietas yang diminta IR 42. Biasanya petani memutuskan varietas yang akan dipergunakan pada saat mulai tanam, sementara PSO tidak menyiapkan (stockis) beraneka ragam varietas. Apabila varietas tidak ada, maka PSO akan membeli atau mendatangkan varietas yang diinginkan dari para penangkar. Oleh karena itu sebaiknya petani peserta mengusulkan verietas benih padi minimal sebulan sebelum pemakaian, sehingga ada waktu bagi PSO untuk mengadakan. Penggadaan benih bersertifikat oleh PSO $60-70$ persen didatangkan dari penangkar setempat. Beberapa jenis varietas yang biasanya diusahakan oleh petani : IR 42, Ciliung, Ciherang. Faktor utama petani menentukan pilihan mempergunakan varietas adalah harga jual dan saat ini varietas padi yang harga jualnya lebih mahal Rp 1.000 sd Rp. 2.000 perkilogram dari varietas lainnya adalah varietas IR 42 . Sementara menurut BBI aneka varietas sudah banyak diusahakan, tetapi petani tidak mau mencoba. Adapun varietas yang sudah pernah dicoba oleh BBI adalah : Ciherang, Ciliung, Situ Bagendit, Inpari 30, 29, 27 dan Inpari 9.

(iv) Sosialisasi. Petani, toko tani bahkan penangkar benih padi tidak mengetahui adanya program subsidi benih dari pemerintah. Ditenggarai hal ini disebabkan tidak aktif dan kreatifnya petugas PPL untuk mensosialisasikannya. Semangat ini juga disebabkan lembaga penyuluh tidak berada dibawah kendali Dinas Pertanian tetapi dibawah komando Bakorluh. Koordinasi diantara kedua lembaga inilah mestinya dioptimalkan agar petani tahu ada bantuan subsidi benih padi.

Informasi lainnya dari penangkar benih padi mengatakan dalam kondisi sekarang penangkar bisa menjual benih secara bebas. Dalam satu kilogramnya biaya yang dikeluarkan oleh penangkar berkisar antara Rp. 6.000 sampai Rp. 6.500 perkilogramnya. Apabila penangkar membeli gabah dari petani, biaya yang dikeluarkan untuk menjadikan benih berkisar Rp. 1.500 perkilogramnya. Benih kemudian disertifikat dengan biaya Rp 7 perkilogramnya. Sertifikat dikeluarkan oleh BPSB dan permintaan BPSB waktu FGD sebaiknya apabila petani mau melakukan sertifikat sebaiknya diajukan pada hari kerja jangan pada hari libur (Sabtu dan Minggu). Sementara lamanya waktu proses sertifikasi rata-rata 5 hari.

Benih yang sudah disertifikat rata-rata dijual ke PSO seharga Rp. 7.500 perkilogram, apabila dijual ke pasar umum bisa sampai Rp. 8.500 perkilogramnya. Agar penangkar bisa mendapatkan keuntungan dan mau menjual ke PSO, maka penangkar mengusulkan PSO bisa 
membeli seharga Rp. 8.800 sd Rp. 9.000 perkilogramnya. Selain ke PSO, petani padi penangkar juga bisa menjual ke Dinas Pertanian melalui sistim kontrak melalui pihak ketiga.

Meskipun subsidi benih tidak mempengaruhi secara nyata dalam struktur ongkos usahatani, tetapi petani masih berharap agar program ini tetap bisa dilanjutkan. Karena diharapkan dengan adanya program bantuan benih petani yang mempergunakan benih bersertifikat semakin banyak. Menurut Dinas Pertanian Provinsi Sumatera Selatan secara keseluruhan petani yang mempergunakan benih bersertifikat baru sekitar 30 persen.

\section{KESIMPULAN}

Subsidi benih padi khususnya di Provinsi Sumatera Selatan masih diperlukan, karena lahan untuk menanam padi sangat luas serta masih banyak petani yang belum mempergunakan benih berlabel dan bermutu dalam bercocok tanam padi. Selain itu dengan adanya kegiatan subsidi benih pengenalan varietas baru yang sudah dihasilkan oleh Litbang dapat lebih ditingkatkan lagi ditingkat petani. Dalam melaksanakan kegiatan subsidi benih kedepannya hendaknya perlu ditingkatkan sosialisasi kegiatan subsidi benih. Khusus untuk daerah pasang surut terutama di Provinsi Sumatera Selatan sebaiknya benih yang dibantu lebih dari $25 \mathrm{~kg}$ perhektar. Pengisian DUPBB yang selama ini untuk satu tahun ditingkatkan menjadi dua tahun dan petani yang sudah menentukan pilihan varietas tidak boleh lagi menukar atau berganti varietas pada pelaksanaannya nanti. Petugas pendata sebaiknya juga diberi insentif tersendiri agar bisa bekerja lebih optimal.

\section{DAFTAR PUSTAKA}

Ashari dan IW. Rusastra. 2014. Pengembangan padi hibrida: pengalaman dari Asia dan prospek bagi Indonesia. Forum Penelitian Agro Ekonomi 32(2): 103-121.

Badan Litbang Pertanian. 2005. Prospek dan Arah Pengembangan Agribisnis Padi. Departemen Pertanian. Jakarta.
[Balitbangtan] Badan Penelitian dan Pengembangan Penelitian. 2015. Deskripsi Varietas Unggul Baru Padi. Badan Penelitian dan Pengembangan Penelitian. Jakarta.

[BPTP Jateng] Balai Pengembangan Teknologi Pertanian Jawa Tengah. 2014. Kumpulan Deskripsi Varietas Padi. Balai Pengembangan Teknologi Pertanian Jawa Tengah. Ungaran.

Direktorat Perbenihan. 2015a. Kompilasi deskripsi padi, JG, UK, KH, KT, talas, gandum, sorgum, kedelai 2015 (s.d. bulan April 2015) (Softcopy). Direktorat Perbenihan. Jakarta.

Dirjen Tanaman Pangan. 2016. Petunjuk Teknis Pelaksanaan Subsidi Benih Tahun Anggaran 2016. Kementerian Pertanian. Jakarta

Hammer, K. 2003. A paradigm shift in the discipline of plant genetic resources. Genetic Resources and Crop Evolution 50:3-10.

Kementerian Pertanian. 2006. Arah dan Strategi Sistem Perbenihan Tanaman Nasional. Jakarta.

Las, I., B. Suprihatno, A.A. Daradjat, Suwarno, B. Abdullah, dan Satoto. 2004. Inovasi teknologi varietas unggul padi: perkembangan, arah, dan strategi ke depan. Dalam F. Kasryno, E. Pasandaran, dan A.M.Fagi (Eds.). Ekonomi Padi dan Beras di Indonesia. Badan Penelitian dan Pengembangan Pertanian. Jakarta. hlm. 375-395.

Priyono, H. 2010. Seminar Nasional Perlindungan Varietas Tanaman ke-5 di Hotel Utami, Sidoarjo (25/11/10).

[Puslitbangtan] Pusat Penelitian dan Pengembangan Tanaman Pangan. 2009. Deskripsi Varietas Unggul Padi 19432009. Pusat Penelitian dan Pengembangan Tanaman Pangan. Bogor. 
Valeriana Darwis: Kendala dan Solusi Implementasi Subsidi Benih...

Robet Asnawi. 2013. Analisis Faktor-Faktor Yang Mempengaruhi Produksi Padi Sawah Inbrida dan Hibrida di Provinsi Lampung. SEPA Vol 10 No 1. 2013. Hal $11-18$

Rogers, E.M. 2003. Diffusion of Innovation. $5^{\text {th }}$ Edition. Free Press. A Division of Simon and Schuster, Inc. New York.
Wale, E. 2011a. Setting the scene for GRPI economics. In E. Wale, A.G. Drucker, and K.K. Zander (Eds.). The Economics Of Managing Crop Diversity On-Farm: Case Studies from the Genetic Resources Policy Initiative. Earthscan Ltd. Londo n, Washington, D.C. p. 3-21. 